\title{
Diversidade genética estimada com marcadores ISSR em populações brasileiras de Zabrotes subfasciatus
}

\author{
Giselle Anselmo de Souza(1), Márcia Rodrigues de Oliveira Carvalho ${ }^{(1)}$, Ernane Ronie Martins ${ }^{(2)}$, \\ Raul Narciso Carvalho Guedes ${ }^{(3)}$ e Luiz Orlando de Oliveira ${ }^{(1)}$
}

\begin{abstract}
(1)Universidade Federal de Viçosa (UFV), Instituto de Biotecnologia Aplicada à Agropecuária, Avenida P.H. Rolfs, s/no, Campus Universitário, CEP 365700-000 Viçosa, MG. E-mail: gansouza@gmail.com, mrocarvalho@terra.com.br, luiz.ufv@hotmail.com (2)Universidade Federal de Minas Gerais, Instituto de Ciências Agrárias, Setor de Fitotecnia, Avenida Osmani Barbosa, s/no, Bairro JK, CEP 39404-006 Montes Claros, MG. E-mail: ernane-martins@ufmg.br (3)UFV, Departamento de Biologia Animal. E-mail: guedes@ufv.br
\end{abstract}

Resumo - O objetivo deste trabalho foi estimar a diversidade genética de populações de Zabrotes subfasciatus, por meio de marcadores moleculares ISSR. Foram avaliadas 12 populações, provenientes de oito estados brasileiros, no total de 269 indivíduos. Cinco iniciadores ISSR permitiram a obtenção do total de 51 fragmentos polimórficos. A percentagem média de locos polimórficos, dentro de cada população, foi de $83,8 \%$. A heterozigosidade corrigida de Nei esperada variou de 0,23 a 0,33 , com média de 0,29 , e o índice de diversidade genética de Shannon e Weaver variou de 0,29 a 0,48, com média de 0,42. No nível de espécie, estes dois índices apresentaram valores de 0,36 e 0,54, respectivamente. A análise de variância molecular mostrou que $66 \%$ da variância molecular total pode ser atribuída a diferenças intrapopulacionais e que os $34 \%$ restantes podem ser atribuídos a diferenças interpopulacionais. $O$ teste de Mantel mostrou baixa correlação entre: distância geográfica e diferenciação genética, identidade genética e diferenciação genética e, distância genética de Nei e diferenciação genética. As populações brasileiras de $Z$. subfasciatus possuem baixa diferenciação genética e fraca estruturação geográfica.

Termos para indexação: caruncho-do-feijão, diferenciação genética, índice de diversidade genética, marcadores ISSR.

\section{Genetic diversity estimated through ISSR markers in populations of Zabrotes subfasciatus}

\begin{abstract}
The objective of this work was to evaluate the genetic diversity of populations of Zabrotes subfasciatus through ISSR molecular markers. Twelve populations from eight Brazilian states were sampled in the total of 269 individuals. Five ISSR primers were used and a total of 51 polymorphic bands were obtained. The percentage of polymorphism within population averaged $83.8 \%$. Nei's unbiased expected heterozygosity ranged from 0.23 to 0.33 , with an average of 0.29 , and the Shannon \& Weaver's index of gene diversity varied from 0.29 to 0.48 , with an average of 0.42 . At species level, these two indexes were 0.36 and 0.54 , respectively. The analysis of molecular variance showed that $66 \%$ of the total molecular variance can be attributed to differences within population, while 34\% was apportioned among populations. Mantel's test showed a low correlation between: geographic distance and genetic differentiation, genetic identity and genetic differentiation, and Nei's genetic distance and genetic differentiation. The genetic differentiation in Brazilian populations of $Z$. subfasciatus is low and geographic structuring is weak.
\end{abstract}

Index terms: bean bruchid, genetic differentiation, genetic diversity index, ISSR markers.

\section{Introdução}

O Brasil se destaca mundialmente como o maior produtor de feijão (Phaseolus vulgaris), entretanto, a cultura ainda apresenta baixa produtividade, quando comparada à de outros países (Abreu, 2005; Borém \& Carneiro, 2006), o que resulta de uma combinação de fatores, entre os quais estão o baixo nível tecnológico empregado no cultivo e a falta de cuidados fitossanitários adequados, tanto durante o ciclo da cultura, quanto no armazenamento dos grãos (Rosolem \& Marubayashi, 1994; Borém \& Carneiro, 2006). Estima-se que entre 20 e $30 \%$ das perdas na produção brasileira possam ser atribuídas às pragas 
que atacam os grãos armazenados (Magalhães \& Carvalho, 1988).

Zabrotes subfasciatus é uma praga que se destaca quanto às perdas durante o armazenamento de grãos de feijão. A espécie é provavelmente originária da América Central e se tornou praga agrícola, quando se estabeleceu e passou a se reproduzir continuamente em grãos armazenados. Difundiu-se pelas regiões tropicais e subtropicais, por meio do comércio de sementes e, atualmente, é cosmopolita e presente nas Américas Central e do Sul, além de estar amplamente distribuída na África, Índia e Região Mediterrânea (Southgate, 1978; Hill, 1990). Os insetos adultos reproduzem-se no campo durante a formação das sementes e, em grãos, durante o período de armazenagem. Com a perfuração causada pelos insetos, os grãos adquirem sabor desagradável e têm seu valor comercial reduzido. Além disso, os insetos consomem as reservas dos cotilédones e comprometem a germinação e o vigor das sementes (Pimbert \& Pierre, 1983; Hill, 1990; Abate \& Ampofo, 1996; Yokoyama, 2006).

Para ser efetivo, o controle de pragas requer entendimento sobre a variação genética dentro e entre populações e sobre a distribuição geográfica desta variação. As interações bioquímicas e moleculares de Z. subfasciatus com seus hospedeiros têm sido intensamente investigadas (Pereira et al., 1995; Mazzoneto, 2002; Sales et al., 2005), no entanto, pouco se sabe sobre a extensão da subdivisão genética dentro de suas populações e entre suas populações. Estudos sobre a variabilidade genética da espécie são relevantes, pois restrições no fluxo gênico entre populações têm papel importante na evolução da adaptação local, o que inclui desenvolvimento de resistência a inseticidas e estabelecimento de raças hospedeiras (GonzálezRodríguez et al., 2002).

Os marcadores moleculares podem ser utilizados como ferramenta para estudos de diversidade genética entre indivíduos, dentro e entre populações ou espécies relacionadas. Aebi et al. (2004) conduziram um estudo com Z. subfasciatus e Z. sylvestris, em que utilizaram uma das classes mais polimórficas de marcadores atualmente disponíveis, os microssatélites, ou "simple sequence repeat" - SSR. Entretanto, os autores detectaram uma deficiência significativa de heterozigotos com os iniciadores avaliados, o que sugere a presença de alelos nulos. Alelos nulos de microssatélites são quaisquer alelos cuja amplificação via PCR falha consistentemente e cuja presença é problemática em análises de dados desta classe de marcadores, pois podem levar à falsa interpretação dos resultados nas análises genéticas (Dakin \& Avise, 2004). O estudo aqui apresentado foi conduzido por meio dos marcadores dominantes ISSR ("inter simple sequence repeat") que, embora sejam reconhecidos como menos polimórficos, foram escolhidos para evitar os problemas que os alelos nulos de microssatélites poderiam trazer para as análises desejadas. Marcadores ISSR não requerem informações prévias de seqüências de DNA da espécie-alvo, produzem fragmentos com grande reprodutibilidade, quando comparados a outros marcadores com base em PCR não-específico como RAPD (Wolfe \& Liston, 1998), por exemplo, e requerem pouca infra-estrutura em termos de equipamento de laboratório para execução dos experimentos.

O objetivo deste trabalho foi estimar a diversidade genética de populações de Z. subfasciatus, por meio de marcadores moleculares ISSR. Os objetivos específicos foram avaliar o nível de variação de ISSRs em Z. subfasciatus, estimar os níveis de partição da variação genética dentro de populações e entre populações, e avaliar se haveria associação significativa entre a distribuição geográfica atual da praga no Brasil e a distância genética no nível de populações.

\section{Material e Métodos}

Amostras de feijão (Phaseolus vulgaris) nãoexpurgado e com sinais de infestação por Zabrotes subfasciatus - presença de ovos ou orifício de emergência de adultos presentes no tegumento dos grãos - foram obtidas de produtores rurais, com histórico de produção própria de sementes e baixa escala de produção, por intermédio das empresas de extensão rural dos estados brasileiros amostrados. Cerca de 250 a $500 \mathrm{~g}$ de grãos foram trazidos do campo para o Laboratório de Biologia Molecular II, no Instituto de Biotecnologia Aplicada à Agropecuária (Bioagro), da Universidade Federal de Viçosa, onde foram mantidas individualizadas e em condições de multiplicação do inseto. Após a primeira eclosão dos ovos em laboratório, os insetos ainda vivos foram fixados em etanol $70 \%$, para etapa posterior de extração de DNA. A identificação do inseto foi confirmada por observação visual de características de morfologia externa, principalmente coxa posterior (Pereira \& Almeida, 2001), sob microscópio estereoscópico. 
Foram avaliados 269 indivíduos de Z. subfasciatus, provenientes de 12 populações, distribuídas em oito estados brasileiros. As coordenadas geográficas dos locais de coleta das amostras (Tabela 1) foram estimadas com base na localização da cidade de origem, por meio do aplicativo Google Earth versão 3.0. Este aplicativo também foi utilizado para o cálculo das distâncias geográficas entre as populações. Os dados de distâncias geográficas foram utilizados para construir uma matriz e correlacioná-la à matriz de diferenciação genética $\left(\mathrm{F}_{\mathrm{ST}}\right)$ das populações.

Com base em modificações do protocolo adotado por Clark et al. (2001), foi extraído o DNA genômico total de cada inseto individualmente e, após a etapa de extração, o DNA foi ressuspenso em tampão TE. A concentração final da solução de DNA extraído de cada amostra foi obtida pela comparação de alíquotas de cada solução com amostras de DNA do fago $\lambda$, cuja concentração era previamente conhecida. O DNA de cada amostra foi então mantido a $-20^{\circ} \mathrm{C}$ para uso subseqüente.

A escolha dos iniciadores de ISSR começou por meio de um teste preliminar de amplificação realizado em 26 deles, provenientes do conjunto 9 da University of British Columbia. A amplificação foi conduzida com DNA amostrado de quatro indivíduos, escolhidos aleatoriamente e provenientes de duas populações distintas. Somente iniciadores que permitissem a obtenção de fragmentos de alta intensidade, quando avaliados em gel de agarose, foram selecionados para a próxima fase de avaliação. Foram selecionados 15 iniciadores entre os 26 testados; os 11 iniciadores restantes foram descartados do estudo, pois não

Tabela 1. Localização das 269 amostras de Zabrotes subfasciatus e tamanho da amostra $(\mathrm{N})$.

\begin{tabular}{lccc}
\hline Localidade & N & Latitude (S) & Longitude (W) \\
\hline Rio Branco, AC (RIB) & 23 & $09^{\circ} 58^{\prime} 51^{\prime \prime}$ & $67^{\circ} 49^{\prime} 13^{\prime \prime}$ \\
Prado, BA (PRA) & 22 & $17^{\circ} 21^{\prime} 04^{\prime \prime}$ & $39^{\circ} 13^{\prime} 09^{\prime \prime}$ \\
Cruz das Almas, BA (CRA) & 21 & $12^{\circ} 40^{\prime} 12^{\prime \prime}$ & $39^{\circ} 06^{\prime} 37^{\prime \prime}$ \\
Laranja da Terra, ES (LAT) & 24 & $19^{\circ} 54^{\prime} 00^{\prime \prime}$ & $41^{\circ} 04^{\prime} 12^{\prime \prime}$ \\
Ordália, GO (ORD) & 24 & $16^{\circ} 12^{\prime} 39^{\prime \prime}$ & $49^{\circ} 44^{\prime} 18^{\prime \prime}$ \\
Itauçu, GO (ITA) & 14 & $1^{\circ} 11^{\prime} 57^{\prime \prime}$ & $49^{\circ} 36^{\prime} 03^{\prime \prime}$ \\
Montalvânia, MG (MON) & 24 & $14^{\circ} 25^{\prime} 42^{\prime \prime}$ & $44^{\circ} 22^{\prime} 34^{\prime \prime}$ \\
Montes Claros, MG (MOC) & 24 & $16^{\circ} 41^{\prime} 33^{\prime \prime}$ & $43^{\circ} 49^{\prime} 47^{\prime \prime}$ \\
Paracatu, MG (PAR) & 22 & $17^{\circ} 12^{\prime} 00^{\prime \prime}$ & $46^{\circ} 52^{\prime} 12^{\prime \prime}$ \\
Ponta Porã, MS (PPO) & 23 & $22^{\circ} 31^{\prime} 51^{\prime \prime}$ & $55^{\circ} 43^{\prime} 49^{\prime \prime}$ \\
Alta Floresta, MT (ALF) & 24 & $09^{\circ} 54^{\prime} 00^{\prime \prime}$ & $55^{\circ} 54^{\prime} 37^{\prime \prime}$ \\
Colorado, PR (COL) & 24 & $22^{\circ} 49^{\prime} 47^{\prime \prime}$ & $51^{\circ} 58^{\prime} 55^{\prime \prime}$ \\
\hline
\end{tabular}

apresentaram produtos de amplificação ou a amplificação foi de intensidade muito fraca.

Em seguida, foram testadas condições de reação, de forma a otimizar as amplificações para cada um dos 15 iniciadores anteriormente escolhidos. Foram testadas diferentes concentrações dos vários componentes de PCR, inclusive: temperatura de hibridação daqueles pré-selecionados $\left(43\right.$ até $\left.56^{\circ} \mathrm{C}\right)$, concentração de $\mathrm{MgCl}_{2}(1,5 \mathrm{mM}$ ou $2 \mathrm{mM})$, concentração de formamida ( 1 ou $2 \%$ ) e quantidade de DNA. Os padrões de fragmentos que cada iniciador produziu, em cada combinação de fatores, foram inspecionados visualmente, tendo-se observado a reprodutibilidade e a intensidade dos fragmentos e a presença de polimorfismo. Finalmente, foram escolhidos cinco iniciadores entre os 15 testados (Tabela 2).

As reações de amplificação foram realizadas em volume total de $15 \mu \mathrm{L}$ e consistiram de: $1 \%$ de formamida (iniciadores 808,811 e 891 ) ou $2 \%$ de formamida (iniciadores 807, 809); $2 \mathrm{mM}$ de $\mathrm{MgCl}_{2}$ (iniciadores 807 , 808,811 e 891 ) ou $2,5 \mathrm{mM}$ de $\mathrm{MgCl}_{2}$ (iniciador 809); 0,5 U de Taq polimerase (Phoneutria); 10 a $20 \mathrm{ng}$ de DNA molde; $0,2 \mathrm{mM}$ de cada dNTP; 0,2 $\mathrm{M}$ de iniciador; $10 \mathrm{mM}$ Tris-HCl pH 8; $50 \mathrm{mM} \mathrm{KCl;} 0,1 \%$ de Tween20; e água ultrapura.

As amplificações foram realizadas em termociclador Modelo 9700. As condições de amplificação foram adaptadas de Huang \& Sun (2000): etapa inicial de desnaturação de $94^{\circ} \mathrm{C}$ por 5 min, seguida por 35 ciclos de $94^{\circ} \mathrm{C}$ por $45 \mathrm{~s}, 45 \mathrm{~s}$ para hibridação do iniciador (com temperatura de hibridação específica para cada um), $72^{\circ} \mathrm{C}$ por 1 min e $50 \mathrm{~s}$, e uma etapa adicional de extensão de $72^{\circ} \mathrm{C}$ por $7 \mathrm{~min}$. Os produtos da amplificação foram separados por eletroforese em gel de agarose 1,5\% em tampão TBE (90 mM Tris-base, $90 \mathrm{mM}$ ácido bórico e 2 mM EDTA), com tensão constante de $110 \mathrm{~V}$. Posteriormente, os géis foram corados em solução de

Tabela 2. Iniciadores ISSR utilizados para amplificação, com temperatura de anelamento (Tm) e número total de fragmentos .

\begin{tabular}{lcc}
\hline Código & Seqüências $\left(5^{\prime}-3^{\prime}\right)$ & Tm $\left({ }^{\circ} \mathrm{C}\right)$ \\
\hline UBC 807 & $(\mathrm{AG})_{8} \mathrm{~T}$ & $50^{\circ} \mathrm{C}$ \\
UBC 808 & $(\mathrm{AG})_{8} \mathrm{C}$ & $54^{\circ} \mathrm{C}$ \\
UBC 809 & $(\mathrm{AG})_{8} \mathrm{G}$ & $51^{\circ} \mathrm{C}$ \\
UBC 811 & $(\mathrm{GA})_{8} \mathrm{C}$ & $51^{\circ} \mathrm{C}$ \\
UBC 891 & $\mathrm{HVH} \mathrm{(TG)})_{7}^{(1)}$ & $47^{\circ} \mathrm{C}$ \\
\hline
\end{tabular}

${ }^{(1)} \mathrm{H}=(\mathrm{A}, \mathrm{C}$ ou $\mathrm{T})$. 
brometo de etídio $0,6 \mathrm{ng} \mathrm{mL} \mathrm{m}^{-1}$. Os fragmentos foram visualizados por meio de luz ultravioleta, e as imagens foram digitalizadas em sistema de captura de imagens. O tamanho dos fragmentos amplificados foi estimado por comparação com marcador molecular de $100 \mathrm{pb}$ DNA Ladder.

Os fragmentos de ISSR foram tratados como marcadores dominantes e julgados como caracteres binários: presente (1) ou ausente (0). Em análises subseqüentes, somente foram considerados os fragmentos polimórficos que puderam ser julgados de forma reproduzível em todos os indivíduos analisados. Fragmentos cuja presença era inconsistente ou que foram observados como fragmentos fracos e de pequena reprodutibilidade, em todos os indivíduos, foram excluídos das análises finais. Uma matriz binária (presença ou ausência do fragmento) foi obtida e com ela estimaramse os índices de diversidade genética dentro de e entre populações. Marcadores dominantes não permitem que os indivíduos heterozigotos sejam distinguidos na amostra estudada. Assim, a frequiência dos alelos em populações com acasalamentos ao acaso, como é o caso das populações de Z. subfasciatus, pode ser inferida pelo equilíbrio de Hardy-Weinberg. O programa POPGENE versão 1.3 (Yeh et al., 1999) foi utilizado para se calcular a estatística da variação genética de cada população pelo pressuposto de que as populações estão em equilíbrio de Hardy-Weinberg. As estimativas incluíram a percentagem de locos polimórficos $(\mathrm{P})$, heterozigosidade esperada $\left(\mathrm{H}_{\mathrm{E}}\right)$ e índice de diversidade genética de Shannon (I).

Estimou-se o valor de diferenciação genética, $\mathrm{F}_{\mathrm{ST}}$, que representa um índice de diferenciação genética da população e determina as proporções da variabilidade genética total que se referem às diferenças genéticas entre populações e às diferenças entre indivíduos (Mork, 2000).

A análise de variância molecular (AMOVA) foi realizada por meio do programa Arlequin versão 3.1 (Excoffier et al., 2005). A árvore filogenética foi obtida pelo método UPGMA ("unweighted pair group method with arithmetic mean") e pelo programa MEGA versão 3.1 (Kumar et al., 2004), a partir dos valores de $\mathrm{F}_{\text {ST. }}$ O teste de Mantel (Mantel, 1967), implementado pela rotina MXCOMP no programa NTSYS-pc, versão $2.2 \mathrm{~K}$, com 9.000 permutações ao acaso, foi usado para investigar a correlação entre $\mathrm{F}_{\mathrm{ST}}$, a identidade genética de Nei e a diversidade genética de Nei, com base nas matrizes cofenéticas.

\section{Resultados e discussão}

Os cinco iniciadores ISSR selecionados permitiram a obtenção de 52 fragmentos, dos quais apenas um foi monomórfico e, portanto, excluído da análise. O número de fragmentos por iniciador variou entre 7 e 13, mas, em média, foram obtidos 10 fragmentos. O polimorfismo dentro de cada população variou de $74,51 \%$ (populações PAR e RIB) a 92,16\% (população ALF), com média de $83,82 \%$ (Tabela 3 ). Estes resultados indicam que os cinco iniciadores utilizados foram satisfatórios para a detecção de polimorfismo, nas populações de Z. subfasciatus analisadas.

Pelo acasalamento ao acaso e o equilíbrio de HardyWeinberg, os valores da heterozigosidade esperada corrigida de $\mathrm{Nei}(1978)\left(\mathrm{H}_{\mathrm{E}}\right)$ variaram de 0,1281 a 0,3281, com média de 0,270 . Os índices de diversidade genética de Shannon \& Weaver (1949) (I) variaram de 0,1893 a 0,4805, com média de 0,3870 (Tabela 3); no nível de espécie, estes dois índices apresentaram valores médios de 0,3626 e 0,5381, respectivamente.

Por meio da AMOVA, foi realizada a partição da variação genética em dois níveis: dentro de populações e entre populações. Essa partição da AMOVA mostrou maior variação genética dentro da população, com $66 \%$ da variação total, e os $34 \%$ da variação genética restante foram observados entre populações. Os valores de variação genética foram significativos

Tabela 3. Diversidade genética dentro de populações de Zabrotes subfasciatus e em nível de espécie ${ }^{(1)}$.

\begin{tabular}{lcccc}
\hline População $^{(2)}$ & $\mathrm{N}$ & $\mathrm{P}(\%)$ & $\mathrm{H}_{\mathrm{E}}$ & $\mathrm{I}$ \\
\hline RIB & 23 & 74,51 & 0,2765 & 0,4074 \\
PRA & 22 & 82,35 & 0,2827 & 0,4228 \\
CRA & 21 & 86,27 & 0,3281 & 0,4795 \\
LAT & 24 & 86,27 & 0,3114 & 0,4608 \\
ORD & 24 & 80,39 & 0,2829 & 0,4187 \\
ITA & 14 & 86,27 & 0,2781 & 0,4230 \\
MON & 24 & 88,24 & 0,2948 & 0,4418 \\
MOC & 24 & 88,24 & 0,2253 & 0,3538 \\
PAR & 22 & 74,51 & 0,2710 & 0,3259 \\
PPO & 23 & 88,24 & 0,3256 & 0,4805 \\
ALF & 24 & 92,16 & 0,2908 & 0,2908 \\
COL & 24 & 78,43 & 0,2953 & 0,4351 \\
\hline Média & 22 & 83,82 & 0,2885 & 0,4117 \\
Espécie & 269 & 100 & 0,3636 & 0,5393 \\
\hline
\end{tabular}

${ }^{(1)} \mathrm{N}$, tamanho da amostra; $\mathrm{P}$, percentagem de polimorfismo; $\mathrm{H}_{\mathrm{E}}$, heterozigosidade esperada corrigida de Nei (1978) (assumido o equilíbrio de Hardy-Weinberg); I, índice de diversidade genética de Shannon \& Weaver (1949). ${ }^{(2)}$ RIB, Rio Branco, AC; PRA, Prado, BA; CRA, Cruz das Almas, BA; LAT, Laranja da Terra, ES; ORD, Ordália, GO; ITA, Itauçu, GO; MON, Montalvânia, MG; MOC, Montes Claros, MG; PAR, Paracatu, MG; PPO, Ponta Porã, MS; ALF, Alta Floresta, MT; COL, Colorado, PR. 
para as duas fontes de variação, com probabilidades calculadas por 1.000 permutações ao acaso. $\mathrm{O}$ valor de diferenciação genética das populações $\left(\mathrm{F}_{\mathrm{ST}}\right)$ foi 0,3358, obtido pela AMOVA, e foi significativo $(\mathrm{p}<0,001)$ com probabilidades calculadas por 1.000 permutações ao acaso. Os valores de $\mathrm{F}_{\mathrm{ST}}$ entre pares de populações variaram de 0,0680 a 0,6165 . Todos os valores encontrados entre pares de populações foram significativos a $5 \%$ de probabilidade.

A identidade genética de Nei, calculada entre pares de populações, variou de 0,7226 (MOC e PPO) a 0,9452 (PRA e MON), valores estes que, por serem próximos a 1, mostram o alto grau de similaridade genética entre as populações avaliadas. A distância genética de Nei, calculada para inferir a divergência genética entre populações, variou de 0,0640 a 0,3250 , e seu menor valor foi observado entre os pares de populações MOC e PRA, enquanto o maior valor foi observado entre os pares MOC e PPO. MOC é uma população originária de Montes Claros, MG, e PRA é originária de Prado, BA, distante quase $500 \mathrm{~km}$ de MOC. PPO está localizada em Ponta Porá, MS, a aproximadamente $1.700 \mathrm{~km}$ de MOC.

Os valores de distância genética de Nei foram empregados para a construção do dendrograma com o método UPGMA (Figura 1). A população ALF, amostrada em Alta Floresta, MT, mostrou-se completamente diferenciada das demais populações analisadas e formou um grupo exclusivo. Com exceção de ALF, a análise do dendrograma identificou dois subgrupos principais, cujas composições mostram que não há relação clara entre distância genética e distância geográfica. O primeiro subgrupo agregou a população amostrada no Acre (RIB), juntamente com populações encontradas nos estados do Paraná (COL), Mato Grosso do Sul (PPO), Goiás (ORD e ITA), Bahia (CRA) e Espírito Santo (LAT). O segundo subgrupo apresentou discreta relação entre distribuição geográfica das populações e composição do subgrupo, uma vez que ele contém populações amostradas em localidades geograficamente próximas, das quais três são do Norte e Noroeste de Minas Gerais (MOC, MON, PAR) e uma do Sul da Bahia (PRA). O teste de Mantel mostrou baixa correlação entre: os valores da distância geográfica e $\mathrm{F}_{\mathrm{ST}},\left(\mathrm{r}=-0,000708, \mathrm{p}\left[\mathrm{Z}_{\mathrm{rdm}} \mathrm{d} \leq \mathrm{Z}_{\mathrm{obs}}\right]=0,5332\right)$; identidade genética de Nei e $F_{S T} \quad(r=-0,24190$, $\left.\mathrm{p}\left[\mathrm{Z}_{\mathrm{rdm}} \mathrm{d} \leq \mathrm{Z}_{\mathrm{obs}}\right]=0,0888\right)$; e distância genética de Nei e $\mathrm{F}_{\mathrm{ST}}\left(\mathrm{r}=0,25470, \mathrm{p}\left[\mathrm{Z}_{\mathrm{rdm}} \mathrm{d} \leq \mathrm{Z}_{\mathrm{obs}}\right]=0,9223\right)$.
Os insetos amostrados para o presente estudo foram obtidos em propriedades rurais com produção própria de sementes e baixa escala de produção. Deliberadamente, não foram amostrados insetos provenientes de produtores com grandes áreas de plantio. A escolha desta estratégia de coleta teve como objetivo maximizar as chances de amostrar insetos provenientes de populações localmente adaptadas e que, potencialmente, poderiam estar sob menor influência de fluxo gênico associado a dispersões recentes, mediadas por atividades humanas. Foram utilizados somente insetos recebidos vivos ou oriundos da primeira eclosão dos ovos, que vieram juntamente com os grãos de feijão das áreas de cultivo. Insetos que surgiram da multiplicação em condições de laboratório foram descartados do estudo, para não alterar as frequiências gênicas originalmente presentes nas populações multiplicadas em condições de campo.

Estudos que tratam da capacidade de dispersão de populações naturais de bruquídeos, especialmente Z. subfasciatus, não estão disponíveis na literatura. Dispersão a longa distância, apenas com auxílio de correntes aéreas, parece ser bastante improvável para bruquídeos, pelo menos assim foi considerado para Acanthoscelides pallidipennis (Tuda et al., 2001).

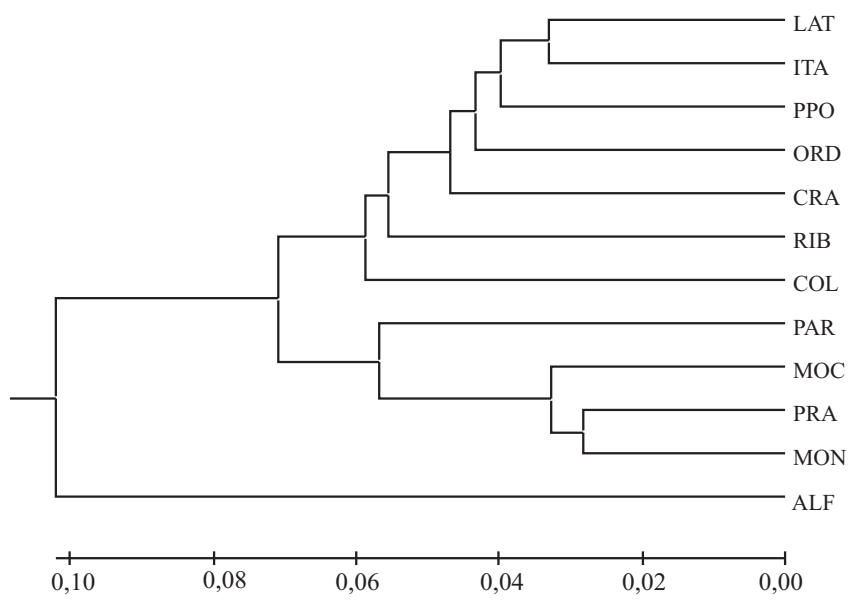

Figura 1. Dendrograma obtido pelo método UPGMA, com base nas distâncias genéticas de Nei (1978), tendo-se utilizado 51 fragmentos de ISSR detectados em 12 populações de Zabrotes subfasciatus. LAT, Laranja da Terra, ES; ITA, Itauçu, GO; PPO, Ponta Porã, MS; ORD, Ordália, GO; CRA, Cruz das Almas, BA; RIB, Rio Branco, AC; COL, Colorado, PR; PAR, Paracatu, MG; MOC, Montes Claros, MG; PRA, Prado, BA; MON, Montalvânia, MG; ALF, Alta Floresta, MT. 
Entretanto, dispersão a longa distância mediada por atividades humanas, como por exemplo, a livre movimentação de grãos não-expurgados pelo território nacional, pode ser um mecanismo facilitador, que permite a Z. subfasciatus colonizar de maneira eficaz novas áreas geográficas, que não poderiam ser atingidas facilmente por meios naturais de dispersão. Os resultados obtidos no presente estudo apóiam a conclusão de que as populações de Z. subfasciatus possuem estruturação genética fraca. Eles indicam que populações próximas, em termos de geografia, não são necessariamente aquelas mais similares quanto à genética, e que a diversidade genética intrapopulacional é pequena e, portanto, há um extenso fluxo gênico contemporâneo entre populações geograficamente distantes.

Vários fatores podem ter contribuído para a baixa diversidade genética e fraca estruturação geográfica detectada neste estudo. Z. subfasciatus não é uma espécie nativa do Brasil, e sua introdução no país tem provavelmente origem recente. É comum encontrar espécies introduzidas com baixos níveis de diversidade genética, pois a diversidade encontrada em áreas recémcolonizadas é composta apenas de uma pequena parcela da diversidade genética existente nos centros de origem, em razão do efeito do fundador (Kim \& Sappington, 2004). Z. subfasciatus se reproduz continuadamente durante o ano, inclusive em hospedeiros alternativos a $P$. vulgaris e $P$. lunatus, seus hospedeiros primários (Hill, 1990). Embora os mecanismos de dispersão a longa distância não sejam conhecidos, uma alta mobilidade local permitiria que indivíduos de $Z$. subfasciatus estabelecessem migrações entre lavouras próximas, o que impediria, assim, o aparecimento de populações geneticamente diferenciadas. Embora este estudo tenha usado somente insetos provenientes de pequenas propriedades rurais, com produção própria de sementes, é possível que outros aspectos não avaliados, como por exemplo, a fonte original das sementes e a proximidade da lavoura das vias de transporte de grãos ou de outras lavouras com histórico de produção distinto tenham influenciado a amostragem de populações geneticamente isoladas.

\section{Conclusões}

1. A variabilidade genética entre as populações brasileiras de Zabrotes subfasciatus é baixa.

2. A variação genética intrapopulacional (66\%) é maior do que a variação genética interpopulacional (34\%).
3. As populações de Zabrotes subfasciatus avaliadas não se apresentam geograficamente estruturadas no Brasil.

\section{Agradecimentos}

À Fundação de Amparo à Pesquisa do Estado de Minas Gerais, pelo apoio financeiro concedido a Luiz Orlando de Oliveira, por meio do PPM CAG APQ0673-3.08/07; à Coordenação de Aperfeiçoamento de Pessoal de Nível Superior e ao Conselho Nacional de Desenvolvimento Científico e Tecnológico, pela concessão de bolsas de estudos de pós graduação a Giselle Anselmo de Souza e Márcia Rodrigues de Oliveira Carvalho, respectivamente.

\section{Referências}

ABATE, T.; AMPOFO, J.K.O. Insect pests of beans in Africa: their ecology and management. Annual Review of Entomology, v.4, p.45-73, 1996.

ABREU, A.F.B.; BIAVA, M. Cultivo do feijão da primeira e segunda safras na Região Sul de Minas Gerais. Santo Antônio do Goiás: Embrapa Arroz e Feijão, 2005. (Embrapa Arroz e Feijão. Sistemas de Produção, 6).

AEBI, A.; SHANI, T.; BUTCHER, R.D.J.; ALVAREZ, N.; RISTERUCCI, A.M.; BENREY, B. Isolation and characterization of polymorphism microsatellite markers in Zabrotes subfasciatus Boheman (Coleoptera: Bruchidae). Molecular Ecology Notes, v.4, p.752-754, 2004.

BORÉM, A.; CARNEIRO, J.E.S. A Cultura. In: VIEIRA, C.; PAULA JÚNIOR, T.J.; BORÉM, A. (Ed.). Feijão. 2.ed. Viçosa: UFV, 2006. p.13-18.

CLARK, T.L.; MEINKE, L.J.; FOSTER, J.E. Molecular phylogeny of Diabrotica beetles (Coleoptera: Chrysomelidae) inferred from analysis of combined mitochondrial and nuclear DNA sequences. Insect Molecular Biology, v.10, p.303-314, 2001.

DAKIN, E.E.; AVISE, J.C. Microsatellite null alleles in parentage analysis. Heredity, v.93, p.504-509, 2004.

EXCOFFIER, L.; LAVAL, G.; SCHNEIDER, S. Arlequin ver. 3.1: an integrated software package for population genetics data analysis. Berne: University of Berne, 2005.

GONZÁLEZ-RODRÍGUEZ, A.; BENREY, B.; CALLEJAS, A.; OYAMA, K. Inter and intraspecific genetic variation and differentiation in the sibling bean weevils Zabrotes subfasciatus and Z. sylvestris (Coleoptera: Bruchidae) from Mexico. Bulletin of Entomological Research, v.92, p.185-189, 2002.

HILL, D.S. Pests of stored products and their control. New York: CRC Press, 1990. 274p.

HUANG, J.C.; SUN, M. Genetic diversity and relationships of sweetpotato and its wild relatives in Ipomoea series Batatas (Convolvulaceae) as revealed by inter-simple sequence repeat (ISSR) 
and restriction analysis of chloroplast DNA. Theoretical and Applied Genetics, v.100, p.1050-1060, 2000.

KIM, K.S.; SAPPINGTON, T.W. Boll weevil (Anthonomus grandis Boheman) (Coleoptera: Curculionidae) dispersal in the Southern United States: evidence from mitochondrial DNA variation. Environmental Entomology, v.33, p.457-470, 2004.

KUMAR, S.; TAMURA, K.; NEI, M. MEGA 3: integrated software for molecular evolutionary genetics analysis and sequence alignment. Briefings in Bioinformatics, v.5, p.150-163, 2004.

MAGALHÃES, B.P.; CARVALHO, S.M. Insetos associados à cultura. In: ZIMMERMANN, M.J.O.; ROCHA, M.; YAMADA, M.R.T. (Ed.). Cultura do feijoeiro: fatores que afetam a produtividade. Piracicaba: Potafos, 1988. p.573-589.

MANTEL, N.A. The detection of disease clustering and a generalized regression approach. Cancer Research, v.27, p.209-220, 1967.

MAZZONETO, F. Efeito de genótipos de feijoeiro e de pós de origem vegetal sobre o controle de Zabrotes subfasciatus (Boh.) e Acanthoscelides obtectus (Say) (Col.: Bruchidae). 2002. 134p. Tese (Doutorado) - Escola Superior de Agricultura Luiz de Queiroz, Piracicaba.

MORK, J. BI 315 lab. course: methods in population genetics. Trondhjem: Department of Botany, Trondhjem Biological Station, 2000. Disponível em: http://folk.ntnu.no/vmbijmor/jmork/courses/ 315H02/00Komp.doc. Acesso em: 15 jan. 2007.

NEI, M. Estimation of average heterozygosity and genetic distance from a small number of individuals. Genetics, v.83, p.583-590, 1978.

PEREIRA, P.A.A.; YOKOYAMA, M.; QUINTELA, E.D.; BLISS, F.A. Controle de caruncho Zabrotes subfasciatus (Bohemann, 1833) (Coleoptera: Bruchidae) pelo uso de proteína da semente em linhagens quase-isogênicas do feijoeiro. Pesquisa Agropecuária Brasileira, v.30, p.1031-1034, 1995.

PEREIRA, P.R.V.; ALMEIDA, L.M. Chaves para a identificação dos principais Coleoptera (Insecta) associados com produtos armazenados. Revista Brasileira de Zoologia, v.18, p.271-283, 2001.
PIMBERT, M.P.; PIERRE, D. Ecophysiological aspects of bruchid reproduction. I. The influence of pod maturity and seeds of Phaseolus vulgaris and the influence of insemination on the reproductive activity of Zabrotes subfasciatus. Ecological Entomology, v.8, p.87-94, 1983.

ROSOLEM, C.A.; MARUBAYASH, O.M. Seja o doutor do seu feijoeiro. Arquivo do Agrônomo, v.7, p.1-18, 1994.

SALES, M.P.; ANDRADE, L.B.; ARY, M.B.; MIRANDA, M.R.; TEIXEIRA, F.M.; OLIVEIRA, A.S.; FERNANDES, K.V.; XAVIER FILHO, J. Performance of bean bruchids Callosobruchus maculatus and Zabrotes subfasciatus (Coleoptera: Bruchidae) reared on resistant (IT81D-1045) and susceptible (Epace 10) Vigna unguiculata seeds: relationship with trypsin inhibitor and vicilin excretion. Comparative Biochemistry and Physiology: Part A, Molecular and Integrative Physiology, v.142, p.422-426, 2005.

SHANNON, C.E.; WEAVER, W.A Mathematical model of communication. Urbana: University of Illinois Press, 1949.

SOUTHGATE, B.J. The importance of the Bruchidae as pests of grain legumes, their distribution and control. In: SINGH, S.R.; EMDEN, H.F. van; TAYLOR, T.A. (Ed.). Pests of grain legumes: ecology and control. London: Academic Press, 1978. p.219-229.

TUDA, M.; SHIMA, K.; JOHNSON, C.D.; MORIMOTO, K. Establishment of Acanthoscelides pallidipennis (Coleoptera: Bruchidae) feeding in seeds of the introduced legume Amorpha fruticosa, with a new record of its Eupelmus parasitoid in Japan. Applied Entomology and Zoology, v.36, p.269-276, 2001.

WOLFE, A.D.; LISTON, A. Contributions of PCR-based methods to plant systematics and evolutionary biology. In: SOLTIS, D.E.; SOLTIS, P.S.; DOYLE, J.J. (Ed.). Molecular systematics of plants II: DNA sequencing. Boston: Kluwer, 1998. p.43-86.

YEH, F.C.; BOYLE, T.Y.Z.; XIYAN, J.M. POPGENE version 131: Microsoft Window-based freeware for population genetic analysis. Edmonton: University of Alberta, 1999.

YOKOYAMA, M. Pragas. In: VIEIRA C.; PAULA JÚNIOR, T.J.; BORÉM, A. (Ed.). Feijão. Viçosa: UFV, 2006. p.357-374.

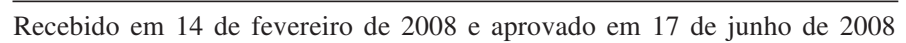

